\title{
SPONTANEOUS PREGNANCY, MACROSOMIA, AND CEPHALOPELVIC DISPROPORTION IN DIFFUSE ADENOMYOSIS: A CASE REPORT
}

\author{
Igor V. LAKHNO ${ }^{1 凶}$, Kemine UZEL ${ }^{2}$ \\ ${ }^{1}$ Kharkiv Medical Academy of Postgraduate Education, Kharkiv, Ukraine \\ ${ }^{2}$ Erzincan University, Erzincan, Turkey
}

Received 09 Febr 2021, Accepted 01 March 2021

https://doi.org/10.31688/ABMU.2021.56.1.14

\begin{abstract}
Introduction. Adenomyosis increases obstetrical and perinatal complications.

Case presentation. We present a rare case of spontaneous pregnancy, large fetus, and cephalopelvic disproportion in a woman with diffuse adenomyosis. No biophysical or biochemical markers of failed placentation were detected during pregnancy. However, delivery was complicated by cephalopelvic disproportion. A male baby of $4350 \mathrm{~g}$ in weight, $59 \mathrm{~cm}$ in length, with a head circumference of $38 \mathrm{~cm}$ and Apgar score of 8 to 9 was delivered via Caesarean. The spontaneous conception and the absence of chronic placental insufficiency were unusual presentations in this case.
\end{abstract}

Conclusions. The fact of complete cervical dilation and cephalopelvic disproportion in diffuse adenomyosis is of great interest. The presented clinical case is a ground for the continuation of the studies in the field of fetal outcome and uterine contractile activity in adenomyosis.

Keywords: adenomyosis, obstetrical complications, uterine contractile activity.

\section{Résumé}

Grossesse spontanée, macrosomie et disproportion céphalopelvienne dans l'adénomyose diffuse: rapport de cas

Introduction. L'adénomyose augmente les complications obstétricales et périnatales.

Présentation du cas. Nous présentons un cas rare de grossesse spontanée, de gros foetus et de disproportion céphalopelvienne chez une femme atteinte d'adénomyose diffuse. Aucun marqueur biophysique ou biochimique d'échec de la placentation n'a été détecté pendant la grossesse. Cependant, l'accouchement a été compliqué par une disproportion céphalopelvienne. Un bébé mâle de $4350 \mathrm{~g}$ de poids, $59 \mathrm{~cm}$ de longueur, avec un tour de tête de $38 \mathrm{~cm}$ et un score d'Apgar de 8 à 9 a été né par césarienne. La conception spontanée et l'absence d'insuffisance placentaire chronique étaient des présentations inhabituelles dans ce cas.

Conclusions. Le fait d'une dilatation cervicale complète et d'une disproportion céphalopelvienne dans l'adénomyose diffuse est d'un grand intérêt. Le cas clinique présenté est un motif pour la poursuite des études dans le domaine de l'évolution foetale et de l'activité contractile utérine dans l'adénomyose. 
Mots-clés: adénomyose, complications obstétricales, activité contractile utérine.

\section{INTRODUCTION}

Adenomyosis is a frequent reproductive female disorder featured by endometrial glands and stroma location in the myometrium. This disease is known to be associated with infertility and adverse pregnancy outcome. The atypical presentation of endometrial tissue induces oxidative stress, chronic inflammation, uterine abnormal peristaltic motility, and disturbed sperm transport ${ }^{1,2}$. Therefore, abnormal implantation, decidualization, and placentation in adenomyosis have a negative impact on fetal well-being and further consequences, according to Barker hypothesis ${ }^{3,4}$.

Disturbed uteroplacental hemodynamics associated with insufficient trophoblastic invasion, fetal growth restriction and pre-eclampsia are well-known complications in diffuse adenomyosis. This thesis was supported by reduced pregnancy-associated placental protein-A (PAPP-A) level and increased pulsatile index $(\mathrm{PI})$ in uterine artery detected in several investigations ${ }^{5,6}$. Preterm birth and preterm rupture of the fetal membrane were also found as reasons for adverse perinatal outcome $\mathrm{e}^{3,4,6-8}$. Thus, any pregnant woman with adenomyosis should have her own individualized programme of management.

We present a rare case of spontaneous pregnancy, large fetus, and cephalopelvic disproportion in a woman with diffuse adenomyosis.

\section{Case presentation}

A primigravida woman, 25-year-old, without pathological history, visited an antenatal clinic because of one-week menstrual delay. She had a 5-year history of adenomyosis treatment. She received dienogest-containing drugs and used a levonorgestrel-releasing intrauterine system. She has not used any contraception for the previous 6 months. An early pregnancy and diffuse adenomyosis penetrating up to the serosal uterine layer were detected via ultrasound (Fig. 1). The uterine size was found rather surprising - up to 14 weeks of gestation. Later on her first-trimester biochemistry and ultrasonographic screenings did not reveal any abnormalities. The cervical length detected via transvaginal ultrasound at 16 weeks of pregnancy was $34 \mathrm{~mm}$. The patient had an increased risk of preterm pregnancy loss and pre-eclampsia. She received dydrogesterone $10 \mathrm{mg}$ twice a day till 16 weeks and $100 \mathrm{mg}$ of acetylsalicylic acid once a day till 36 weeks of gestation. All routine laboratory tests throughout the pregnancy were normal. No comorbidities were found. The variables of uteroplacental, umbilical, and fetal hemodynamics detected via Doppler ultrasound were normal at 26 weeks. No signs of chronic placental insufficiency were found via ultrasound at 32 weeks. The normal fetal status and macrosomia were detected via ultrasound at 38 weeks of gestation (the biparietal diameter was 110 $\mathrm{mm})$. She had a spontaneous onset of labour at 39 weeks, but delivery was complicated by cephalopelvic disproportion. A male baby of $4350 \mathrm{~g}$ in weight, 59 $\mathrm{cm}$ in length, with a head circumference of $38 \mathrm{~cm}$ and Apgar score of 8 to 9 was delivered via Caesarean. The thickness of the lower uterine segment was 4 $\mathrm{cm}$. The uterine atony was unresponsive to uterotonics (carbetocin) and intrauterine balloon. Therefore, a hysterectomy was performed. The removed uterus was enlarged up to 24 weeks of gestation and has diffuse adenomyotic inclusions (Fig. 2). The postoperative period had not complications and the patient has been discharged in 7 days.

\section{Discussion}

The spontaneous conception and absence of chronic placental insufficiency were unusual presentations in this case. The adequate gestational transformation of uteroplacental vessels was supported by normal first trimester PAPP-A and reduced Doppler ultrasound variables of PI in the uterine artery. The large fetus is not typical for diffuse adenomyosis ${ }^{2,4,7}$. The activity of the angiogenic factors was a possible compensatory mechanism responsible for the trophoblastic invasion. Chorionic and placental polypeptide growth factors and antioxidants also could be thought to ameliorate placentation ${ }^{3,5}$. Therefore, the abnormal myometrial structure did not induce any placental disorders.

The complete cervical dilation and cephalopelvic disproportion in diffuse adenomyosis is of great interest. The lack of pressure from the fetal-presenting part could not contribute to the dilation of the cervix in this case. Thus, myometrial contractions played the main role in the process of cervical reconstruction. The vascular system of the myometrium, but not an intrauterine pressure, was a possible conductor of the force of uterine contraction to achieve cervical dilation ${ }^{9,10}$. The stretching of the myometrium by increased intravascular blood volume could play the role of a pacemaker for the global uterine contraction ${ }^{9,11}$. Therefore, increased uterine-wall tension is possible to induce contractions. The further 


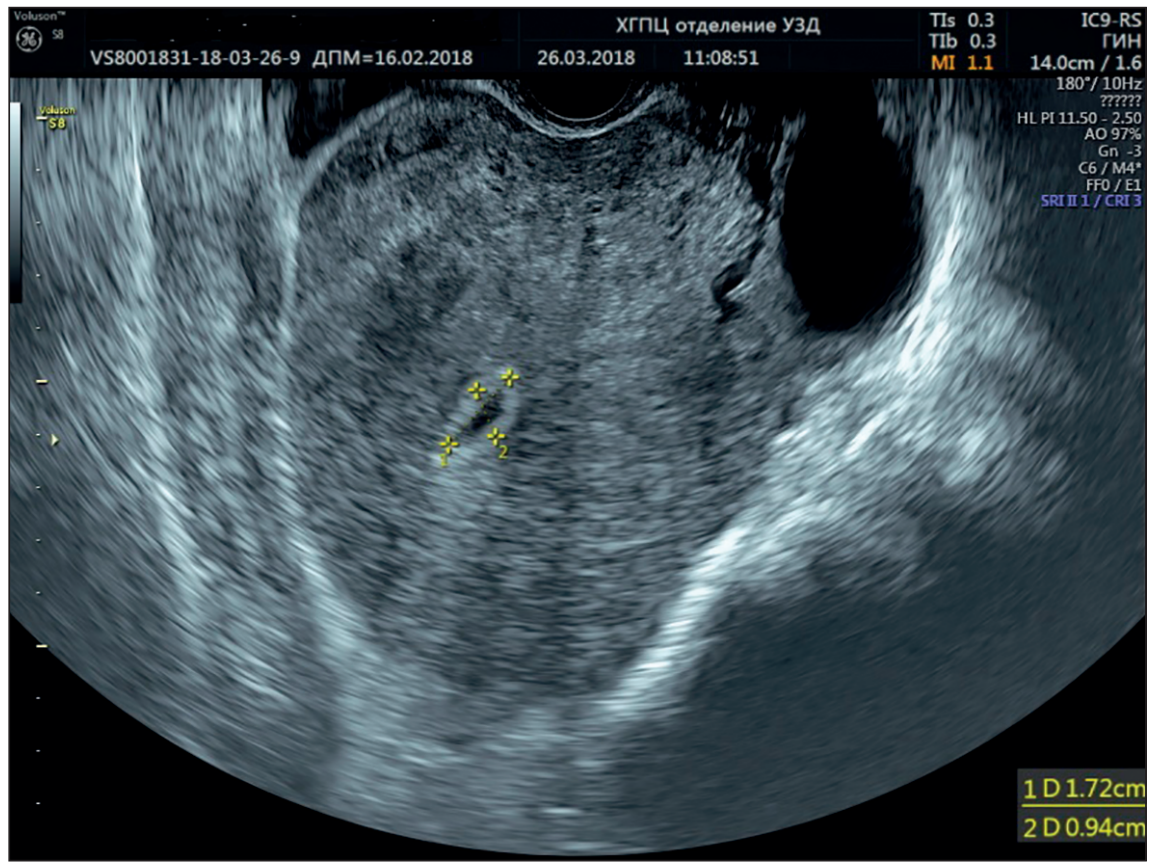

Figure 1. Transvaginal ultrasonography. Early pregnancy and diffuse adenomyosis.

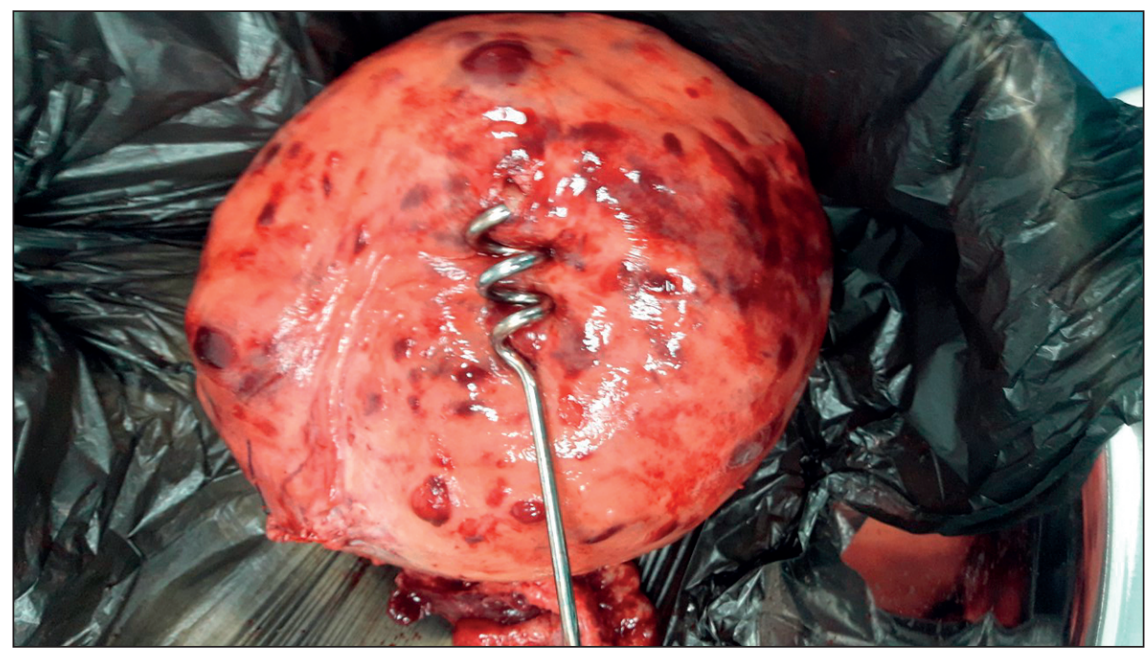

Figure 2. The removed uterus with visible subserous adenomyotic inclusions.

progress of cervical dilation could be related to intrauterine hemodynamics. The vascular system of the myometrium could be hypothesized as a mechanic transducer of the uterine contraction on the way to complete cervical dilation, but fundamental studies are necessary to support this assumption.

\section{Conclusions}

Diffuse adenomyosis is a convenient model for the prediction of some obstetrical and perinatal complications. The presented clinical case is a ground for the continuation of the studies in the field of fetal outcome and uterine contractile activity in adenomyosis.

\section{Author Contributions:}

I.L. and K.U. were responsible for the diagnostic procedures, clinical diagnosis, and treatment decisions. K.U. made the histopathological diagnosis, I.L. performed the surgery. I.L. and K.U. wrote the manuscript. Both authors have read and agreed to the published version of the manuscript.

\section{Compliance with Ethics Requirements:}

"The authors declare no conflict of interest regarding this article"

"The authors declare that all the procedures and experiments of this study respect the ethical standards in the Helsinki Declaration of 1975, as revised in 2008(5), as 
well as the national law. Informed consent was obtained from the patient included in the study"

The ethical approval to report this case was obtained from the Bioethics Committee of the Kharkiv Medical Academy of Postgraduate Education (registration number 0116U002865).

"No funding for this study"

\section{Acknowledgements:}

None

\section{References}

1. Buggio L, Monti E, Gattei U, Dridi D, Vercellini P. Adenomyosis: fertility and obstetric outcome. A comprehensive literature review. Minerva Ginecol. 2018; 70(3):295-302.

2. Vannuccini S, Petraglia F. Recent advances in understanding and managing adenomyosis. F1000Res. 2019;8. pii: F1000 Faculty Rev-283.

3. Horton J, Sterrenburg M, Lane S, Maheshwari A, Li TC, Cheong Y. Reproductive, obstetric, and perinatal outcomes of women with adenomyosis and endometriosis: a systematic review and meta-analysis. Hum Reprod Update. 2019 pii: $\mathrm{dmz} 012$.

4. Scala C, Leone Roberti Maggiore U, Racca A, Barra F, Vellone VG, Venturini PL, Ferrero S. Influence of adenomyosis on pregnancy and perinatal outcomes in women with endometriosis. Ultrasound Obstet Gynecol. 2018;52(5):666-671.

5. Bruun MR, Arendt LH, Forman A, Ramlau-Hansen CH. Endometriosis and adenomyosis are associated with increased risk of preterm delivery and a small-for-gestational-age child: a systematic review and meta-analysis. Acta Obstet Gynecol Scand. 2018;97(9):1073-1090.

6. Razavi M, Maleki-Hajiagha A, Sepidarkish M, Rouholamin S, Almasi-Hashiani A, Rezaeinejad M. Systematic review and meta-analysis of adverse pregnancy outcomes after uterine adenomyosis. Int J Gynaecol Obstet. 2019;145(2):149-157.

7. Cozzolino M, Basile F, Pontrelli G. Effects of adenomyosis on obstetric outcomes. Minerva Ginecol. 2019;71(2):146-154.

8. Harada T, Taniguchi F, Amano H, et al; Japan Environment and Children's Study Group. Adverse obstetrical outcomes for women with endometriosis and adenomyosis: A large cohort of the Japan Environment and Children's Study. PLoS One. 2019;14(8):e0220256.

9. Savitsky AG, Savitsky GA, Ivanov DO, Mikhailov AV, Kurganskiy AV, Mill KV. The myogenic mechanism of synchronization and coordination for uterine myocytes contractions during labor. J Matern Fetal Neonatal Med. 2013;26(6):566-70.

10. House M, Paskaleva A, Myers K, Craigo S, Socrate S. The connection between uterine contractions and cervical dilation: the biomechanics of cervical deformation. American Journal of Obstetrics $\mathcal{E}$ Gynecology. 2015; 93 (6): S55.

11. Young RC. Mechanotransduction mechanisms for coordinating uterine contractions in human labor. Reproduction. 2016;152(2): R51-61. 